\title{
The Process Design and Rapid Superplastic Forming of Industrial AA5083 for a Fender with a Negative Angle in a Small Batch
}

\author{
Zhihao Du ${ }^{1, *(D)}$, Guofeng Wang ${ }^{2}$ and Hailun Wang ${ }^{2,3}$ \\ 1 School of Mechanical and Electric Engineering, Nanyang Normal University, Nanyang 473061, China \\ 2 School of Material Science and Engineering, Harbin Institute of Technology, Harbin 150001, China; \\ gfwang@hit.edu.cn (G.W.); hlwyhzs@163.com (H.W.) \\ 3 Capital Aerospace Machinery Corporation Limited, Beijing 100071, China \\ * Correspondence: duzhihaohit@126.com; Tel.: +86-377-6351-3563
}

Citation: Du, Z.; Wang, G.; Wang, H. The Process Design and Rapid Superplastic Forming of Industrial AA5083 for a Fender with a Negative Angle in a Small Batch. Metals 2021, 11, 497. https://doi.org/10.3390/ met11030497

Academic Editors: Diego Celentano and Anders E. W. Jarfors

Received: 26 January 2021

Accepted: 14 March 2021

Published: 17 March 2021

Publisher's Note: MDPI stays neutral with regard to jurisdictional claims in published maps and institutional affiliations.

Copyright: (c) 2021 by the authors. Licensee MDPI, Basel, Switzerland. This article is an open access article distributed under the terms and conditions of the Creative Commons Attribution (CC BY) license (https:// creativecommons.org/licenses/by/ $4.0 /)$.

\begin{abstract}
A front automobile fender with a negative angle was trial produced via rapid superplastic forming (SPF) technology. The tensile test of industrial AA5083 was carried out at elevated temperatures, and the results showed that the maximum elongation was $242 \%$ at $480{ }^{\circ} \mathrm{C} / 0.001 \mathrm{~s}^{-1}$. A rigid-plastic constitutive model of the SPF process was established. Initial dies of preforming and final forming were designed. The finite element method (FEM) was used to simulate the forming process and predict the thickness distribution of different areas. Furthermore, the dies were optimized to make the thickness distribution uniform. In the final structure, the maximum thinning ratio decreased from $83.2 \%$ to $63 \%$ due to the optimized design of the forming dies. The front automobile fender was then successfully fabricated by the preforming process and final forming process at $480^{\circ} \mathrm{C}$. A thickness measurement was carried out, and the minimum thickness of the preforming structure was $2.17 \mathrm{~mm}$ at the transverse tank, while that of the final structure was $2.49 \mathrm{~mm}$ near the edge of the lamp orifice. The average grain size grew from 20 to $35 \mu \mathrm{m}$. The grain growth led to the reduction of mechanical properties. Compared with the mechanical properties of the initial material, the maximum decrease in tensile strength for the material after superplastic forming was $5.78 \%$, and that of elongation was $18.5 \%$.
\end{abstract}

Keywords: AA5083; rapid SPF; FEM; mechanical property; microstructure evolution

\section{Introduction}

Due to its high specific strength, high specific stiffness, excellent corrosion resistance, and mechanical properties, AA5083 has been in the spotlight of railway vehicles, shipbuilding, and other industries [1-4]. Many investigations have been conducted to determine the influencing factors such as superplasticity and the superplastic forming (SPF) of AA5083 [5-11]. The chemical composition optimization of AA5083 has been attempted to reduce cost [5], and the superplastic deformation behavior was analyzed [6]. The SPF of AA5083 has been widely used to fabricate automotive liftgates and decklids [7], "high-end" automobiles [10], and components for aircraft applications [11].

The front fender is considered an essential part needed to protect nearby components and support other exteriors; however, it is the most challenging part to manufacture due to its complex shape and requirement for high machining accuracy [12-14]. The conventional forming process of a fender was the cold stamping of steel [15] and plastic injection molding [16]. Cold stamping has the disadvantages of spring-back and a high die cost, while injection molding has complex forming processes [17]. SPF has the advantages of low die costs, eliminating spring-back, and producing complex components [18]. Moreover, SPF is an effective forming process for lightweight alloys for automotive components [19]. Thus, SPF, in theory, could be used to fabricate the automotive fender of AA5083. 
Jarrar et al. [20] investigated the superplastic forming of triangular channels with sharp radii, and the forming process was simulated. Zhang et al. [21] researched the controlling of the thickness distribution in superplastic forming. In comparison, a large thickness deviation existed in the produced part. As such, direct-reverse SPF was adopted to make the thickness more uniform [22-24]. Xing et al. [22] proposed a simple and efficient preform design method to improve the uniformity of wall thickness. Lan et al. [24] investigated the two-stage superplastic forming of a V-shaped aluminum sheet into a trough with a deep and irregular contour, and a superior thickness profile was provided. Another limitation of SPF was the slow forming rate, which made it inefficient. Thus, it was necessary to investigate the rapid direct-reverse SPF process for an automobile front fender with a negative angle.

This manuscript aimed to fabricate a complex-shaped front automobile fender by the rapid direct-reverse SPF technology. The tensile test of an industrial AA5083 was carried out at elevated temperatures, and a constitutive equation in SPF was established. With the help of FEM, the forming process and the dies were established. The front automobile fender was then successfully manufactured by rapid SPF technology. A thickness measurement was made, and both the macroscopic and the microstructure behaviors were investigated.

\section{Experimental}

An industrial AA5083 sheet was used in this study, and the thickness of the sheet was $4 \mathrm{~mm}$. The sheet was provided by the Northern Light Alloy Company Ltd. (Harbin, China), and the chemical composition is shown in Table 1. Figure 1 shows the initial microstructure of AA5083, and it can be seen that the grain size was about $20 \mu \mathrm{m}$. The grain size of less than $10 \mu \mathrm{m}$ is typically one of the requirements for superplasticity [18], and this grain size was larger than that in other research papers investigating the superplasticity and SPF of AA5083 [25-28].

Table 1. Chemical composition of AA5083.

\begin{tabular}{cccccccc}
\hline Elements & $\mathbf{S i}$ & $\mathbf{F e}$ & $\mathbf{C u}$ & $\mathbf{M n}$ & $\mathbf{M g}$ & $\mathbf{C r}$ & $\mathrm{Al}$ \\
\hline $\begin{array}{c}\text { Content } \\
(\mathrm{wt} \%)\end{array}$ & 0.073 & 0.18 & 0.020 & 0.68 & 4.66 & 0.074 & Bal. \\
\hline
\end{tabular}

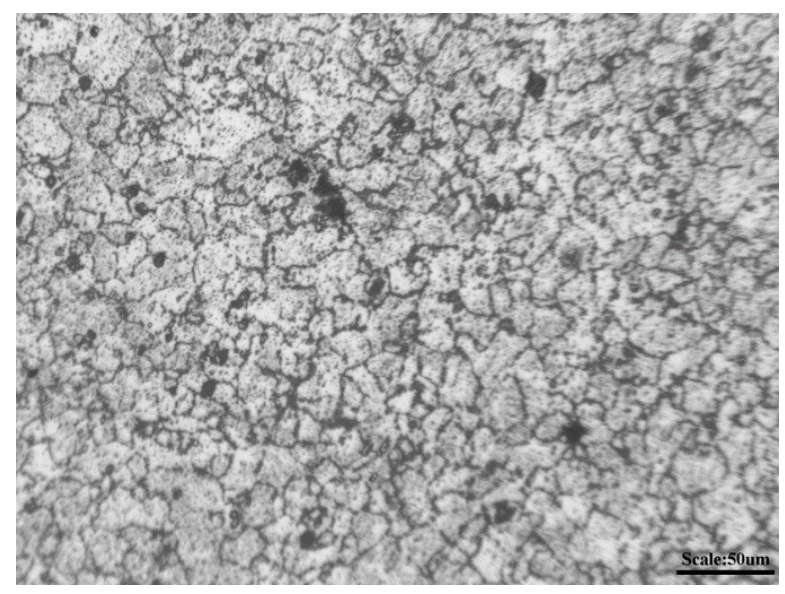

Figure 1. Initial microstructure of AA5083.

Tensile test specimens were cut parallel to the rolling direction, and the gauge size was $15 \mathrm{~mm} \times 5 \mathrm{~mm} \times 4 \mathrm{~mm}$. Tensile tests at elevated temperatures of $400-560{ }^{\circ} \mathrm{C}$ with an interval of $40^{\circ} \mathrm{C}$ were carried out at the strain rate of $5 \times 10^{-3} \mathrm{~s}^{-1}-5 \times 10^{-4} \mathrm{~s}^{-1}$, and the tests were conducted on an Instron 3343 testing machine (Instron Corporation, Norwood, MA, USA). The temperature diversity was less than $3{ }^{\circ} \mathrm{C}$ along the gauge length. The tensile tests at room temperature were conducted on the AG-X Plus testing machine, and 
the tensile strain rate was $1.67 \times 10^{-3} \mathrm{~s}^{-1}$. These specimens were cut from the initial sheet and the sheet after the forming process. To ensure the accuracy of tensile data, at least three tensile tests were performed for each condition, and the intermediate data at each condition were selected as the final result. The stress-strain data were captured at $10 \mathrm{~Hz}$ to guarantee the continuity of the data.

Rapid SPF of the fender was carried out on a 10,000 kN SPF machine. This rapid SPF process was divided into two stages: the preforming process and the final forming process. Each stage was composed of drawing and SPF, and the forming temperature was $480^{\circ} \mathrm{C}$. The target strain rate of the SPF process was $1 \times 10^{-3} \mathrm{~s}^{-1}$.

The microstructural sample was cut into small pieces of $5 \mathrm{~mm} \times 4 \mathrm{~mm} \times \mathrm{T} \mathrm{mm}$ (where $\mathrm{T}$ is the thickness of different regions) by electron discharge wire cutting, then the plane of $5 \mathrm{~mm} \times 4 \mathrm{~mm}$ was mechanically ground using $\mathrm{SiC}$ paper (from $400 \#$ to 2000\#). Subsequently, the sample was electrolytically polished. The samples were corroded with Keller reagent for $60 \mathrm{~s}$ then cleaned with alcohol and distilled water. Scanning electron microscope (SEM) analysis of the microstructure of the as-received material, the preforming structure, and the final forming structure was performed on the Quanta 200 FEG-SEM machine (FEI company, Hillsboro, OR, USA).

\section{Results and Discussion}

\subsection{Flow Stress of AA5083 at Elevated Temperatures}

The flow stress curves of AA5083 at the strain of $5 \times 10^{-3} \mathrm{~s}^{-1}-5 \times 10^{-4} \mathrm{~s}^{-1}$ are shown in Figure 2. The flow stress was dependent on the temperature, strain rate, and true strain. The tensile strength decreased with increasing temperatures and decreasing strain rates, while the elongation increased firstly then reduced with the increasing temperature.
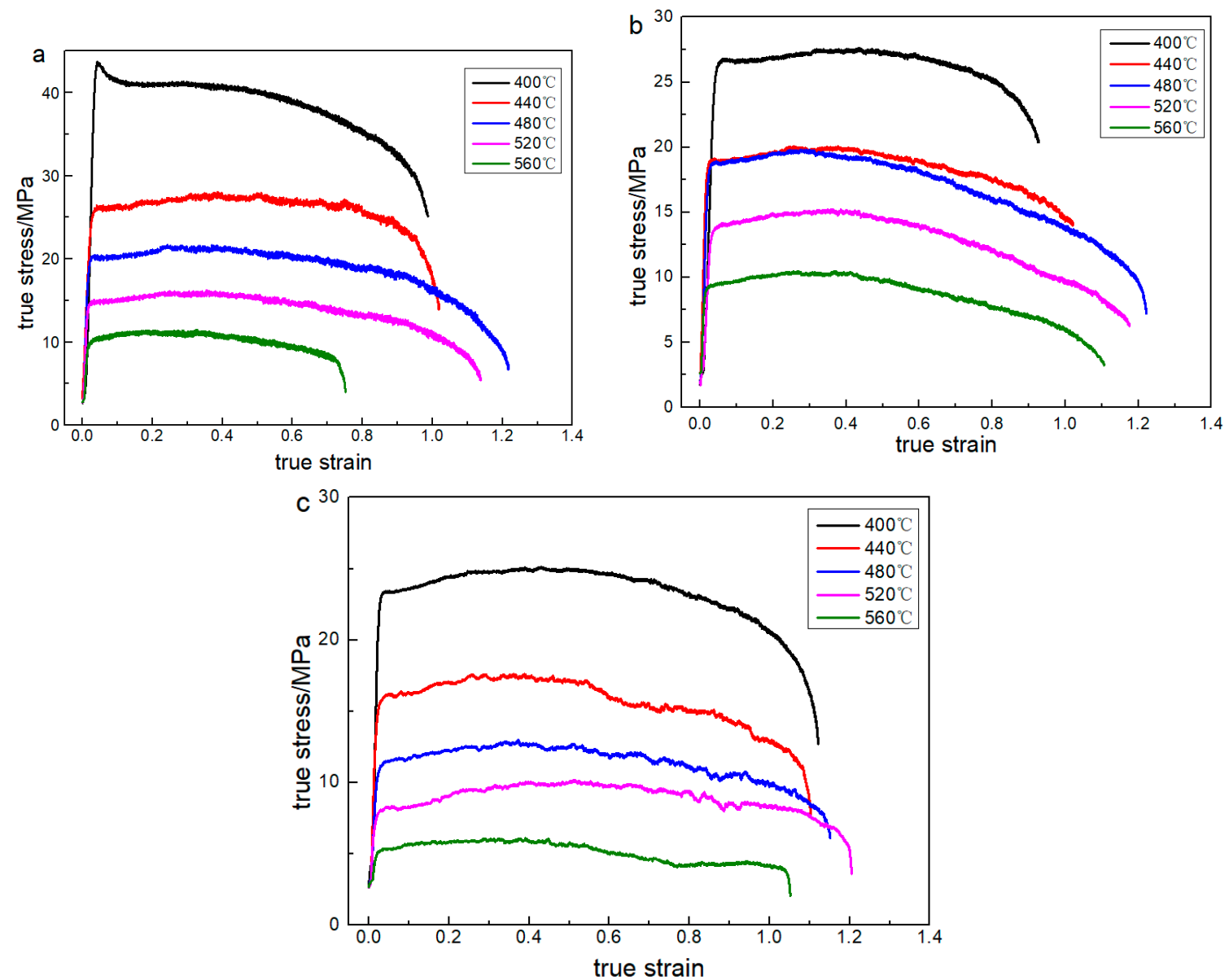

Figure 2. Flow stress curves of AA5083 at: (a) $0.005 \mathrm{~s}^{-1}$; (b) $0.001 \mathrm{~s}^{-1}$ (c) $0.0005 \mathrm{~s}^{-1}$. 
It can be seen that the elongation at some deformation parameters was more than $200 \%$ from Figure 2, and the maximum elongation obtained at $480{ }^{\circ} \mathrm{C}$ and $1 \times 10^{-3} \mathrm{~s}^{-1}$ was $242 \%$. Thus, it can be concluded that the industrial AA5083 exhibited superplastic-like large elongation. This superplastic-like elongation of coarse-grained aluminum alloys with a grain size of more than $10 \mu \mathrm{m}$ has been reported in other investigations [29-31].

In the SPF process, the strain hardening was neglected. Thus, the constitutive model used to describe the SPF process was set as:

$$
\sigma=K \dot{\varepsilon}^{m}
$$

where $m$ is the strain rate sensitivity coefficient indicated the effect of strain rate on the flow stress. $K$ is the material constant related to the deformation temperature and the microstructure. Equation (1) was taken for the logarithms, then it was expressed as:

$$
\ln \sigma=\ln K+m \ln \dot{\varepsilon}
$$

For Equation (2), after being differential, the equation for $m$ can be obtained as:

$$
m=\frac{\partial \ln \sigma}{\partial \ln \dot{\varepsilon}}
$$

The value of $m$ was then calculated to be about 0.35 , and $K$ was estimated to be $155 \mathrm{MPa} \cdot \mathrm{s}$ on account of the flow stress curves at $480^{\circ} \mathrm{C}$ with different strain rates. When the strain rate sensitivity exponent was 0.35 , it was the value of the solute drag creep, which is different from the value indicating grain boundary sliding [32]. This value was lower than in the case of the fine-grained materials [33]. Furthermore, superplastic forming by solute drag creep has been reported by Honda Motor Co., Ltd. (Tokyo, Japan) and UACJ as high-temperature, high-speed blow forming. Thus, the material in this paper could be applied to the SPF process.

\subsection{Structural Design and Process Optimization}

The forming process of the fender is complex. Moreover, it is difficult to observe the deformation and the variation of thickness in the manufacturing process. Thus, the forming process was simulated by FEM, and the thickness distribution of the forming process was predicted, providing a theoretical reference for the final manufacturing process. The conventional SPF cannot achieve the final shape in one process due to the complex shape; thus the whole process included two steps. The first step was the preforming process, which comprised the drawing and the reverse superplastic bulging. The second step was the final process, consisting of the drawing and the direct superplastic bulging.

\subsubsection{Initial Design}

The initial designs of the male die for the preforming process and the male die for the final forming process are shown in Figure 3. To ensure the thickness uniformity of the final product, appropriate material storage was prepared on the preformed male die. Storage tanks were mainly set in A, B and C parts, as shown in Figure 3a). The male die of the final forming shown in Figure $3 \mathrm{~b}$ was mainly used for further stretching and as supplementing material for the superplastic bulging of the final process.

The numerical simulation of the forming process was carried out by the MSC.MARC software (2010, MSC software Corporation, LA, USA). The initial model of the FEM analysis is shown in Figure 4. The color scales represent the plate thickness, and the units of the legend in each figure are millimeters. The dies were rigid, and the sheet was deformable in this model. The size of the sheet was $1900 \mathrm{~mm} \times 2500 \mathrm{~mm}$. The four-node shell element was selected to represent the sheet. The size of the shell element was $20 \mathrm{~mm} \times 20 \mathrm{~mm}$, and the number of the four-node shell element was 11,875 . The thickness was set to be $3 \mathrm{~mm}$. The friction coefficient between the die and the face sheet was set as 0.3 , and the Coulomb friction model was selected to be the friction model. 
a

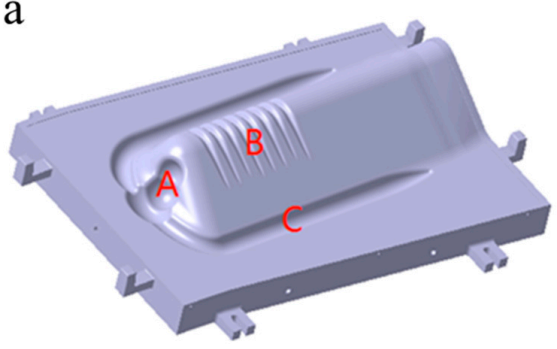

b

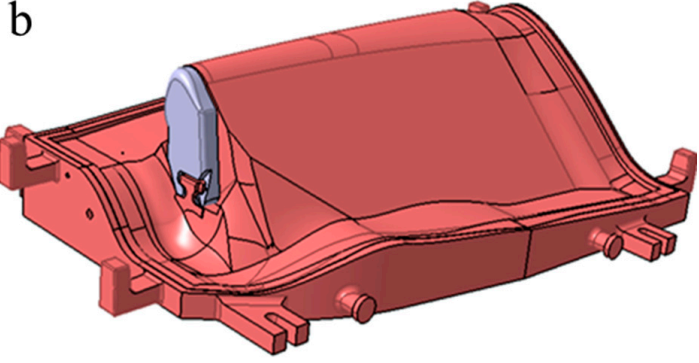

Figure 3. Male dies of (a) the preforming process; (b) final forming process.

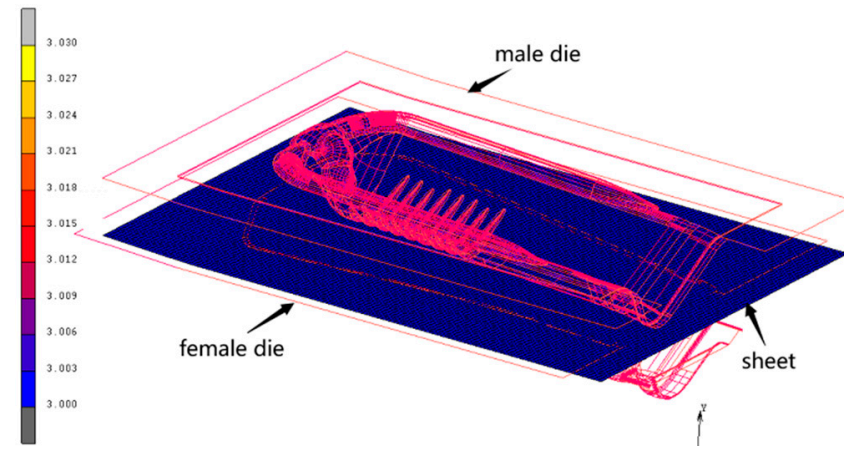

Figure 4. Initial FEM model.

(1) Drawing of the preforming process

The drawing depth was $250 \mathrm{~mm}$. The thickness distribution of the drawing during the preforming process is shown in Figure 5. It can be seen that the minimum thickness at the lowest position of the drawing was $2.78 \mathrm{~mm}$. The radial tensile stress of the material at this position was greater than the tangential compressive stress. Therefore, this resulted in thickness reduction, but the plate thickness reduction rate was only $7.33 \%$.

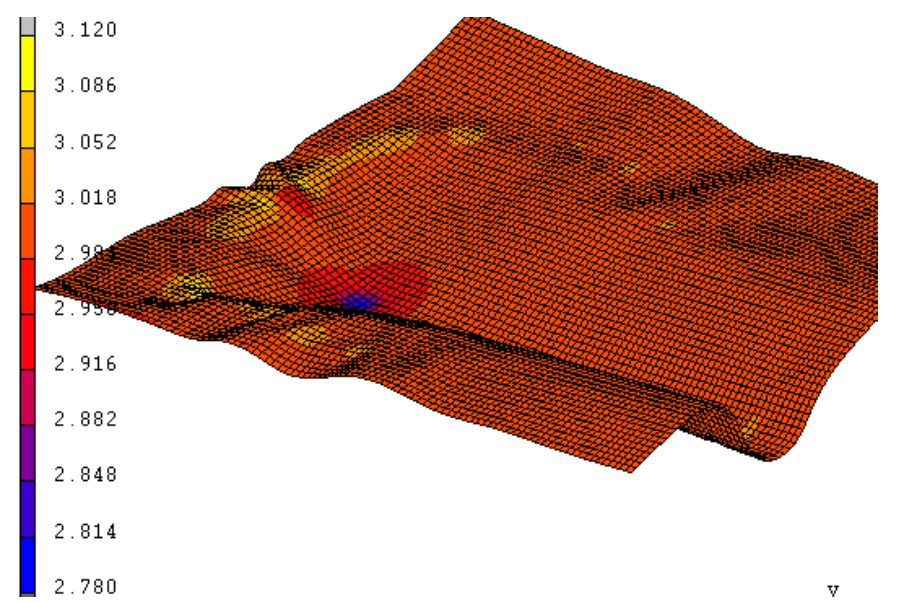

Figure 5. Thickness distribution of the drawing during the preforming process.

(2) Reverse superplastic bulging of the preforming process

The thickness distribution of the reverse superplastic bulging is shown in Figure 6. The minimum thickness was $1.631 \mathrm{~mm}$ at Region $\mathrm{A}$, and the thinning ratio reached was $45.6 \%$. The serious thickness reduction at this region resulted from the thickness reduction in the drawing of the preforming process and the further reduction in bulging. 


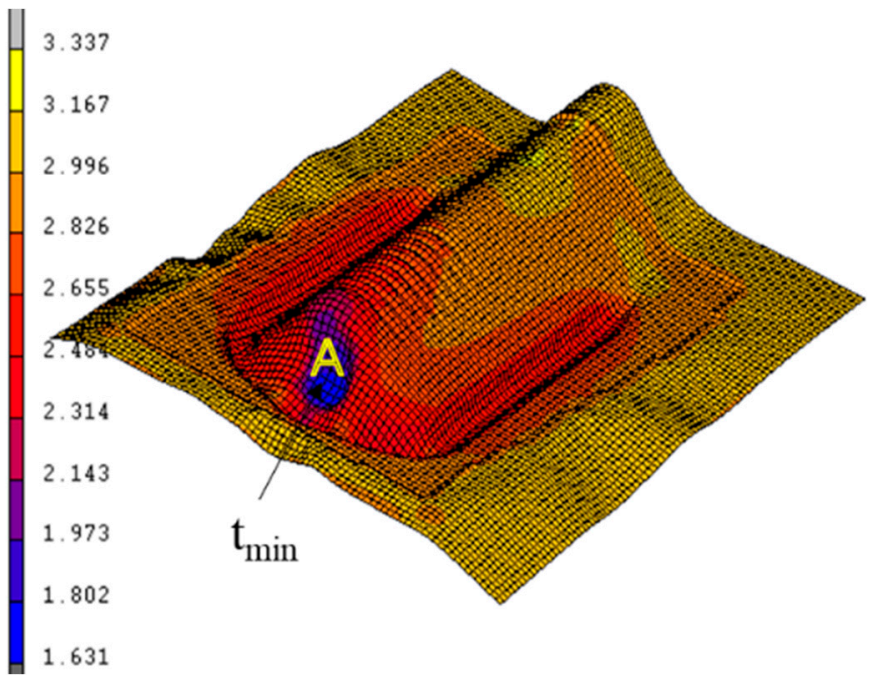

Figure 6. Thickness distribution of the drawing during the preforming process.

(3) Drawing of the final forming process

A finite element analysis of the drawing was carried out, and the results are shown in Figure 7. The hot drawing depth of the final forming was $380 \mathrm{~mm}$. The minimum thickness was reduced from 1.631 to $1.608 \mathrm{~mm}$ due to the stretching of the storage tank. In addition, the material of the storage tank at Region $C$ in the preform process was provided to supply the drawing, and it decreased the thickness reduction. Hence, the thickness at the lowest point of the drawing was $2.106 \mathrm{~mm}$.

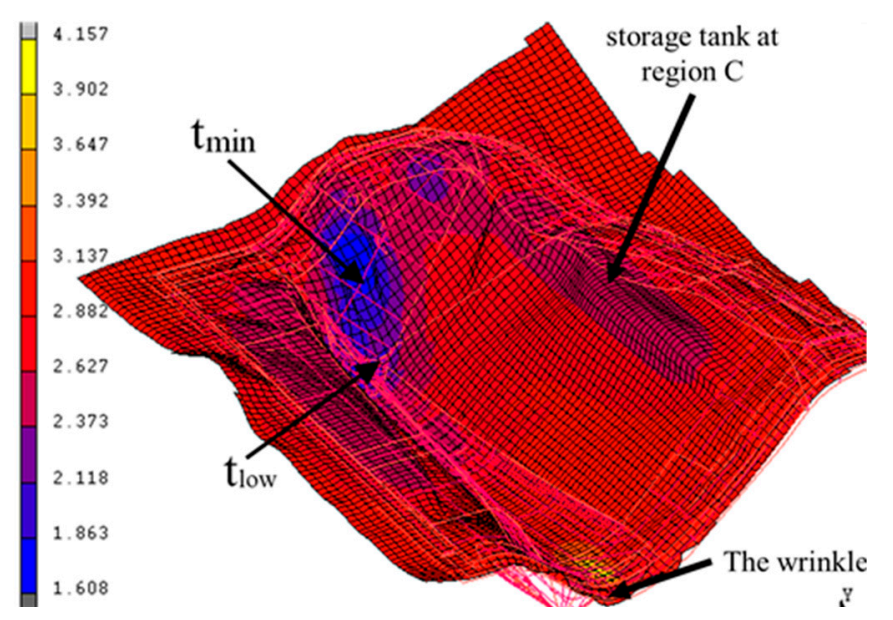

Figure 7. Thickness distribution of the drawing during the final forming process.

\section{(4) Superplastic bulging of the final forming process}

The thickness distribution of the SPF process and the contour of the fender are shown in Figure 8. It can be found that the complex surfaces such as the negative angle at the lamp mouth, the wheel mouth plane, and the steps were formed at the last stage. The minimum thickness occurred at the edge of the lamp mouth. The maximum thickness reduction ratio was $83.2 \%$, and it was so severe that the material could not meet this requirement. 


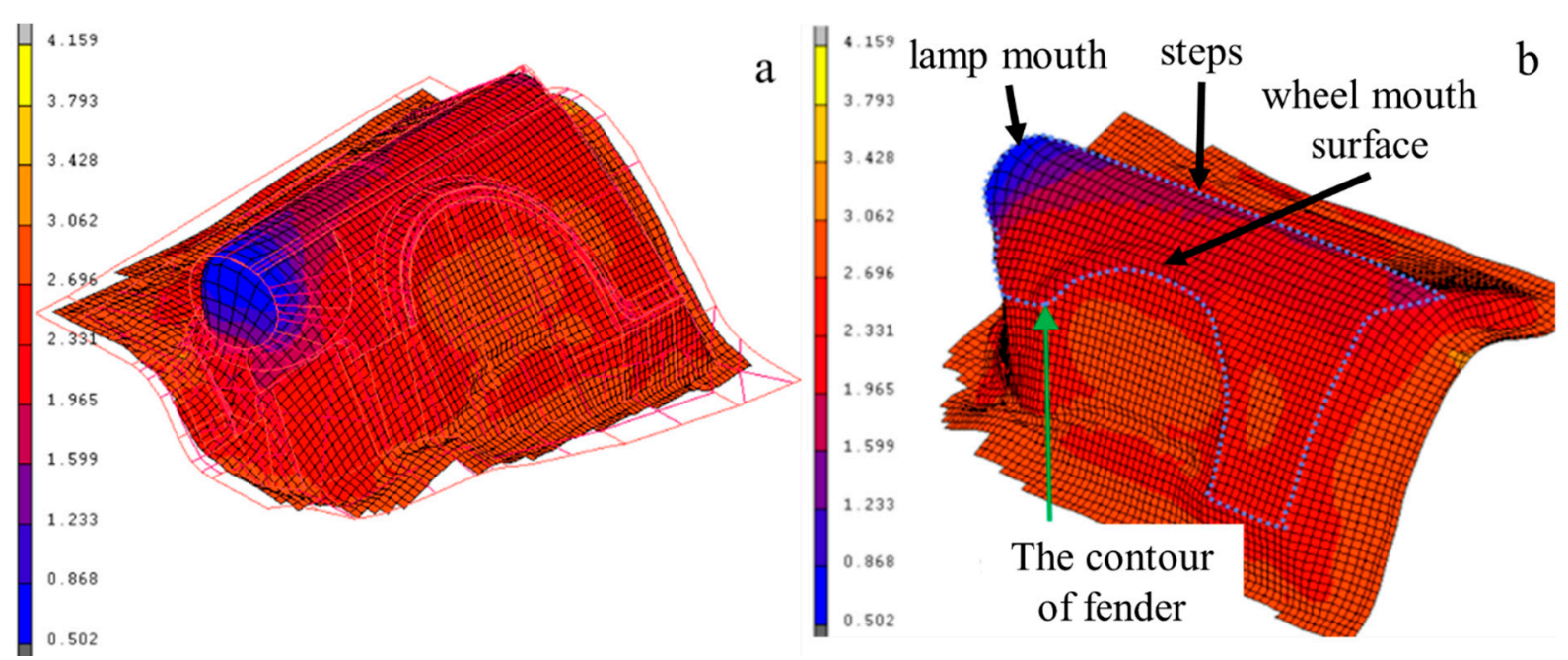

Figure 8. (a) Thickness distribution of the direct superplastic bulging; (b) contour of the fender.

\subsubsection{Optimized Design}

In order to optimize the process and make the thickness more uniform, the preformed die was redesigned. The stamping depth of the preformed die was increased, and the preformed material storage tanks were also added to provide sufficient material for the final product. The optimized preformed die is shown in Figure 9. The drawing depth was increased to $300 \mathrm{~mm}$, material storage tanks near Region B were added, and the width of Region A was also increased.
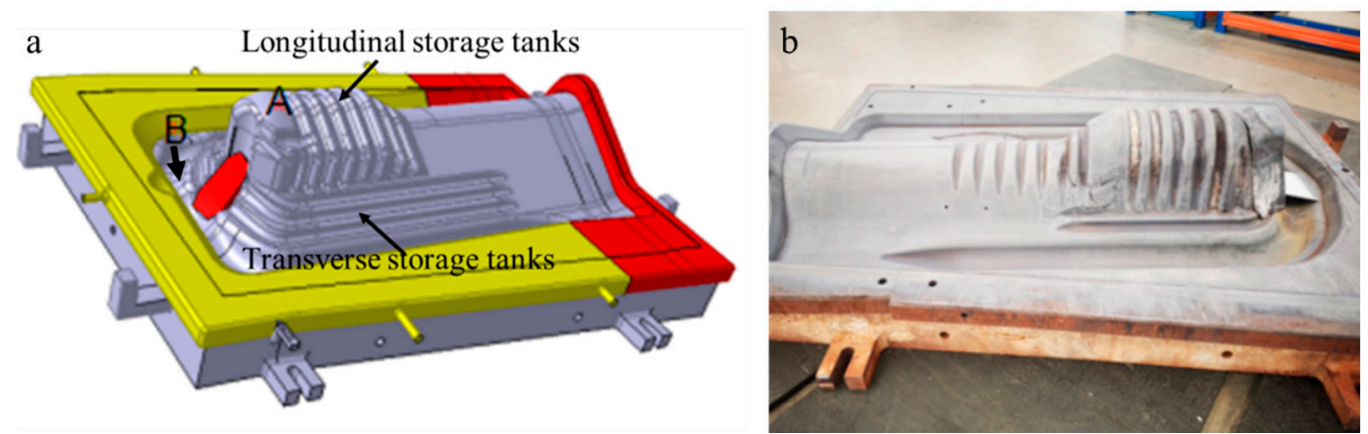

Figure 9. Male die of the preforming process: (a) optimized model; (b) machined die.

(1) Drawing of the preforming process

The thickness distribution resulting from the preforming process drawing after the optimized design is shown in Figure 10. During the stamping process, it was found that the minimum thickness was $2.736 \mathrm{~mm}$, and it occurred at the lowest point of the drawing. The maximum thickness reduction ratio was $8.8 \%$, and no cracks and other defects occurred. Simultaneously, a wrinkle was observed at Region A. Thus, the drawing rate needed to be controlled strictly to reduce wrinkle defects. 


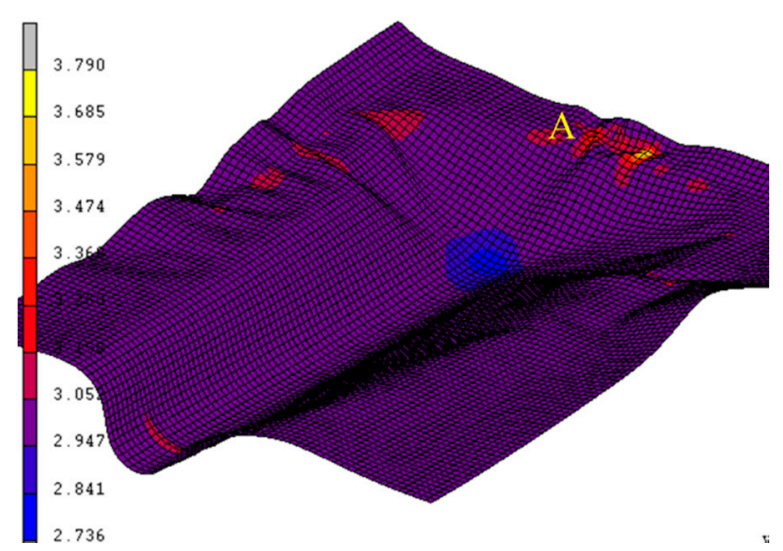

Figure 10. Thickness distribution of the drawing in the preforming process by the optimized design.

(2) Reverse bulging of the preforming process

The thickness distribution after reverse bulging is shown in Figure 11. It can be seen that the thickness diversity increased due to the complex shape of the female die and the improved storage tanks. The minimum thickness was $1.937 \mathrm{~mm}$ in Region A, and the minimum thickness was $2.23 \mathrm{~mm}$ at the longitudinal storage tanks and $2.26 \mathrm{~mm}$ at the transverse storage tanks, respectively. Though the thickness at different regions was nonuniform, it was still greater than $1.9 \mathrm{~mm}$. In addition, there are wrinkles at Regions B and $\mathrm{E}$. The wrinkle at Region B could be flattened in the final forming process, while the deformation at Region $\mathrm{E}$ had little effect on the forming process.

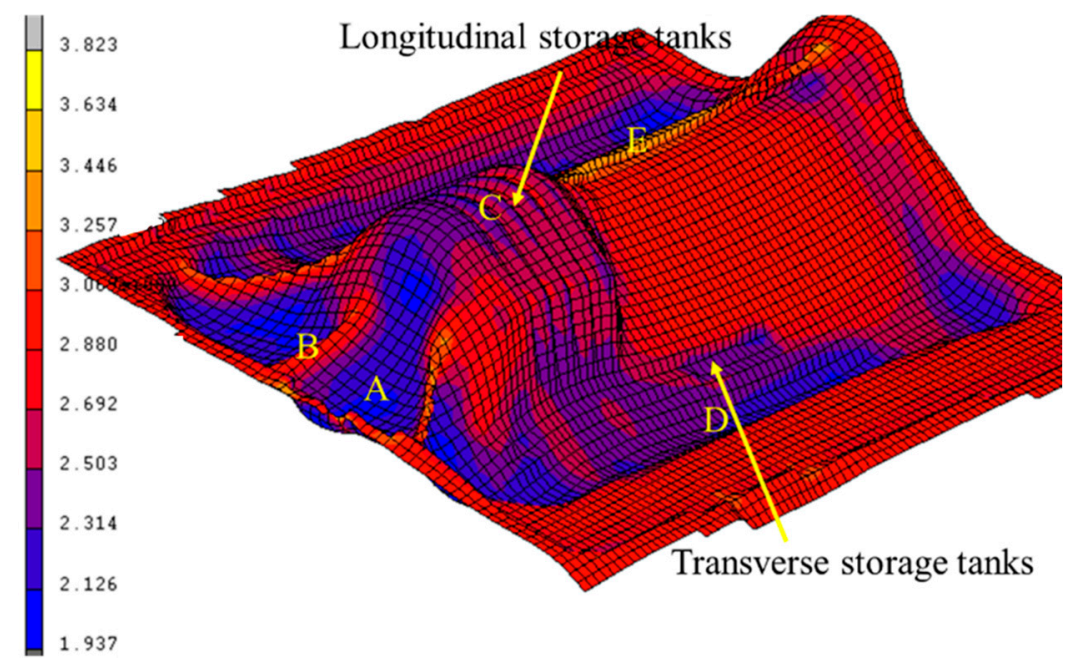

Figure 11. Thickness distribution of reverse bulging during the preforming process.

(3) Drawing of the final forming process

The maximum drawing depth of the final forming was $380 \mathrm{~mm}$, and the minimum thickness at the initial stage of the drawing was $1.94 \mathrm{~mm}$. The thickness distribution of the drawing at the beginning and at the end of the drawing is shown in Figure 12. The storage tanks expanded to supply more material for the next forming process, and the minimum thickness increased slightly to $1.98 \mathrm{~mm}$. It can be seen in Figure $12 \mathrm{~b}$ that the preformed storage tanks still retained a specific shape. 


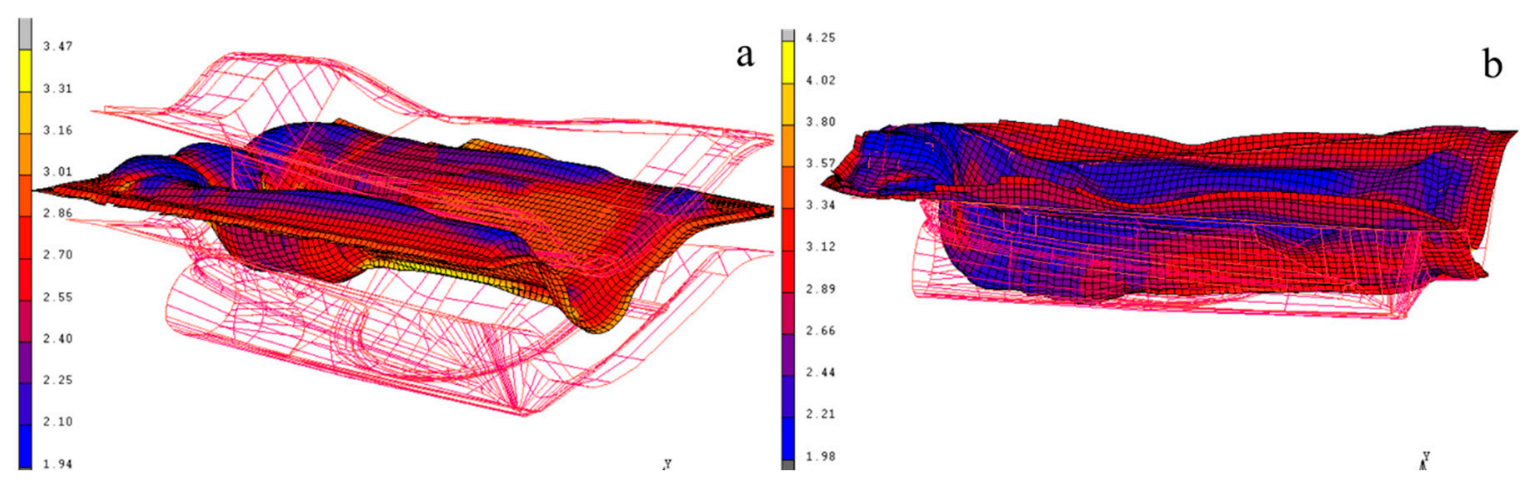

Figure 12. Thickness distribution of the drawing during the final forming process: (a) beginning; (b) end.

(4) SPF of the final forming process

SPF of the final forming process is shown in Figure 13. The wrinkled area at the end of the preformed structure had been flattened by the air bulging. When the fender was fully formed, the minimum thickness occurred at the lamp orifice, and the thickness reduction ratio was $63 \%$. Compared to the thickness distribution of the initial design, the minimum thickness increased by $0.6 \mathrm{~mm}$, indicating that the optimization of the preforming male die was effective. It was also observed that small fillet thickness was more than $2.25 \mathrm{~mm}$, which could guarantee the uniformity of the thickness and part performance.
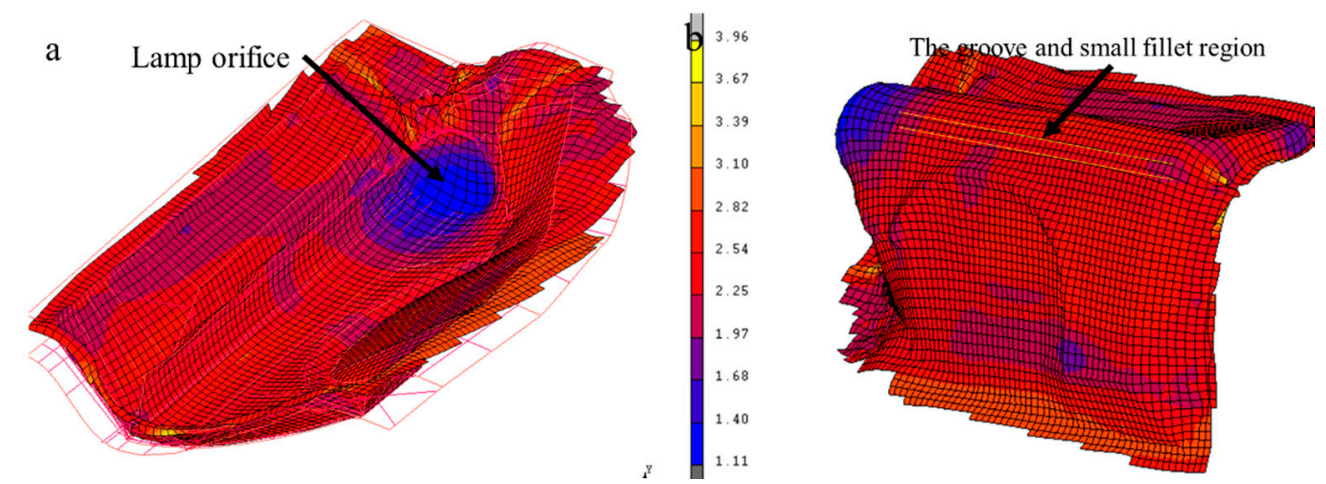

Figure 13. Thickness distribution of superplastic forming (SPF) during the final forming process. (a)interior perspective; (b) lateral perspective.

It was concluded that the optimized design could increase the minimum thickness of the final structure, and the optimized design had more feasibility than the original design in regards to fabricating the fender.

\subsection{Rapid SPF of the Front Fender}

Based on the FEM results of the optimized design, the dies required to fabricate the fender were machined consistently with the dies of the optimized design. The front fender was then trial produced on the SPF machine, with the forming temperature set to be $480^{\circ} \mathrm{C}$.

\subsubsection{Thickness Distribution}

\section{(1) Preforming process}

Figure 14 illustrates the measured points and the thickness distribution of the preforming structure. The structure after reverse superplastic bulging is shown in Figure 14a. Although wrinkles were observed, no crack appeared, indicating that superfluous material was supplied to some regions during the forming process. The thicknesses of three different areas were measured and are shown in Figure $14 \mathrm{~b}-\mathrm{d}$. The results showed that the minimum thickness of the end was $2.34 \mathrm{~mm}$, and the " $\mathrm{W}$ " shape of the thickness distribution was 
presented. Furthermore, the thickness measurement of the storage tanks showed that the thickness was more than $3.0 \mathrm{~mm}$ at the longitudinal tanks, and the minimum thickness of the transverse tanks was $2.17 \mathrm{~mm}$.

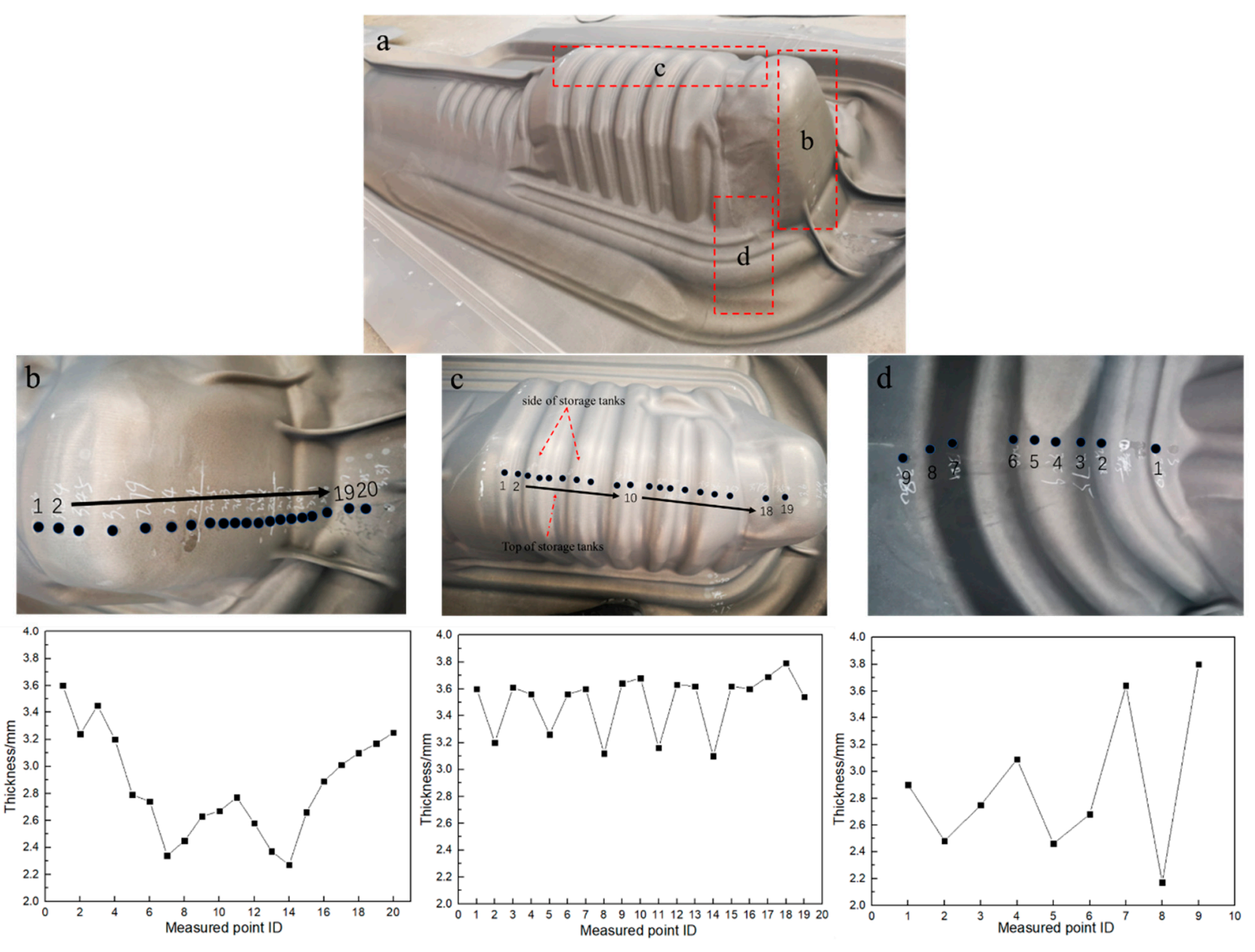

Figure 14. Measurement point ID and thickness: (a) preforming structure; (b) end; (c) longitudinal storage tanks; (d) transverse storage tanks.

\section{(2) Final forming process}

Figure 15 illustrates the measured points of the structure obtained after the final forming and the thickness of each point. The thickness measurement showed that the thickness was almost more than $2.5 \mathrm{~mm}$, and the thickness gradually reduced as the measured points approached the lamp orifice. The thickness reduction resulted from the large deformation at the lamp orifice, and the thickness distribution meets the demand for service. It can also be seen that the facet of the wheel opening contacted the female mold of the final forming process. Furthermore, the long groove and small fillet were formed completely. 

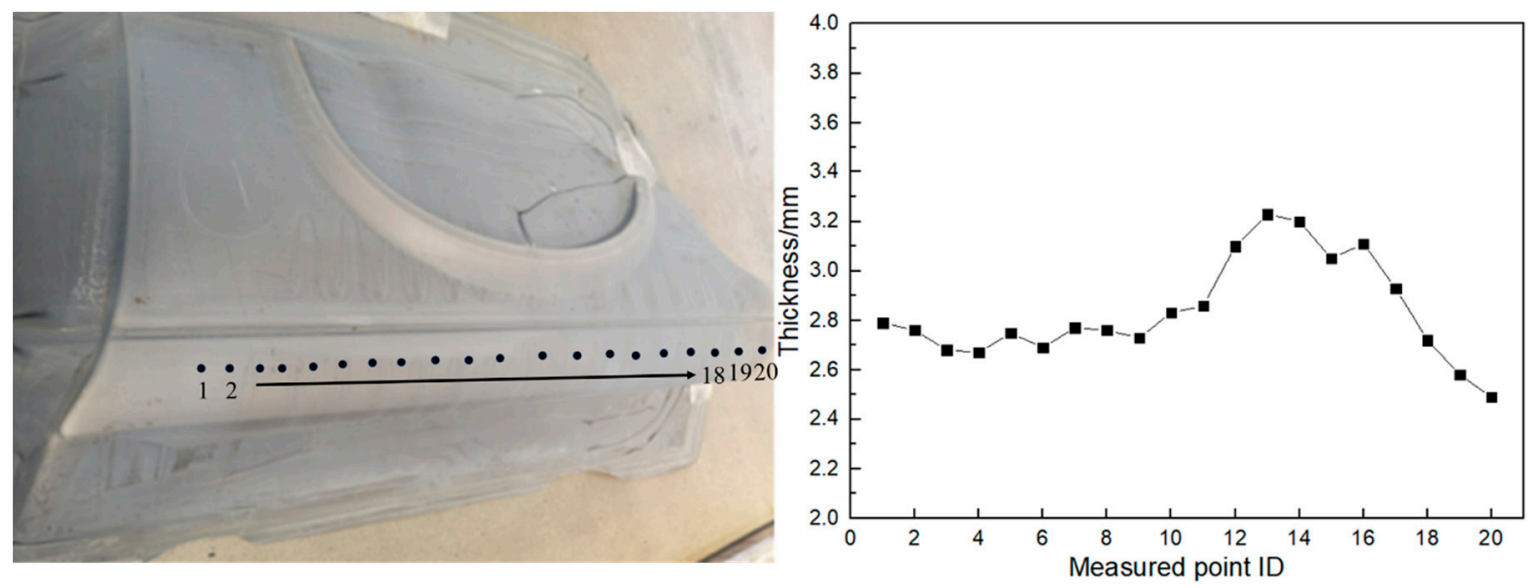

Figure 15. Final structure and thickness measurement points.

The final structure was wire cut and etched, as shown in Figure 16. The front automobile fender was successfully trial produced.
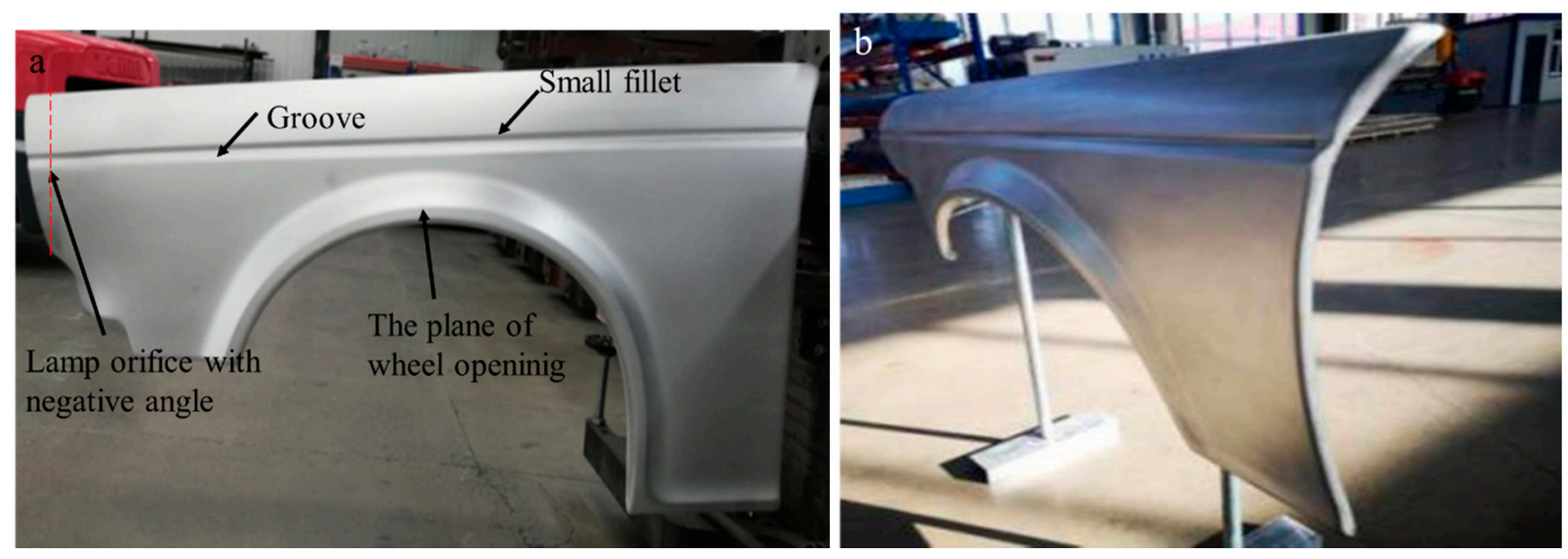

Figure 16. Front automobile fender: (a) elevation view; (b) side view.

\subsubsection{Macro/Micro Performance of the Postmaterial}

The elongation, tensile strength, and yield stress of the postforming material at different regions are shown in Figure 17. The result showed that the tensile strength of the original material was $294 \mathrm{MPa}$, the yield stress was $143 \mathrm{MPa}$, and the elongation was about $31 \%$. The minimum tensile strength of the post-formed material was $277 \mathrm{MPa}$, and the minimum yield stress was $115 \mathrm{MPa}$ at the transverse tank, while the minimum elongation was $24.9 \%$ at the lamp orifice. The measured tensile strength, yield stress, and elongation of the postformed material ranged between 270 and $284 \mathrm{MPa}, 115$ and $121 \mathrm{MPa}$, and 24.9 and $26.6 \%$, respectively. The mechanical performance decreased after the rapid SPF process due to the grain growth resulted from the long exposure to elevated temperature and deformation.

The microstructures of the material at two stages are shown in Figure 18. The initial grain size was about $20 \mu \mathrm{m}$ in Figure 1. Hence, based on the comparison between Figures 1 and 18, it can be concluded that the grain size increased by $5 \mu \mathrm{m}$ after the preforming process and then further increased by $10 \mu \mathrm{m}$ after the final forming process. There is grain size growth resulting from the long time exposure at elevated temperature in the preforming process and the final forming process. 


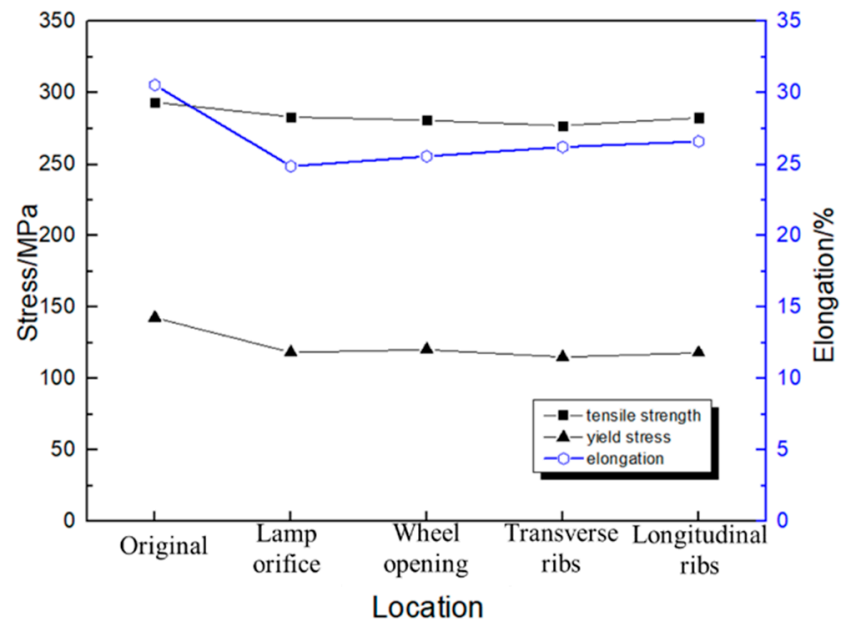

Figure 17. Mechanical properties of the material after the forming process.
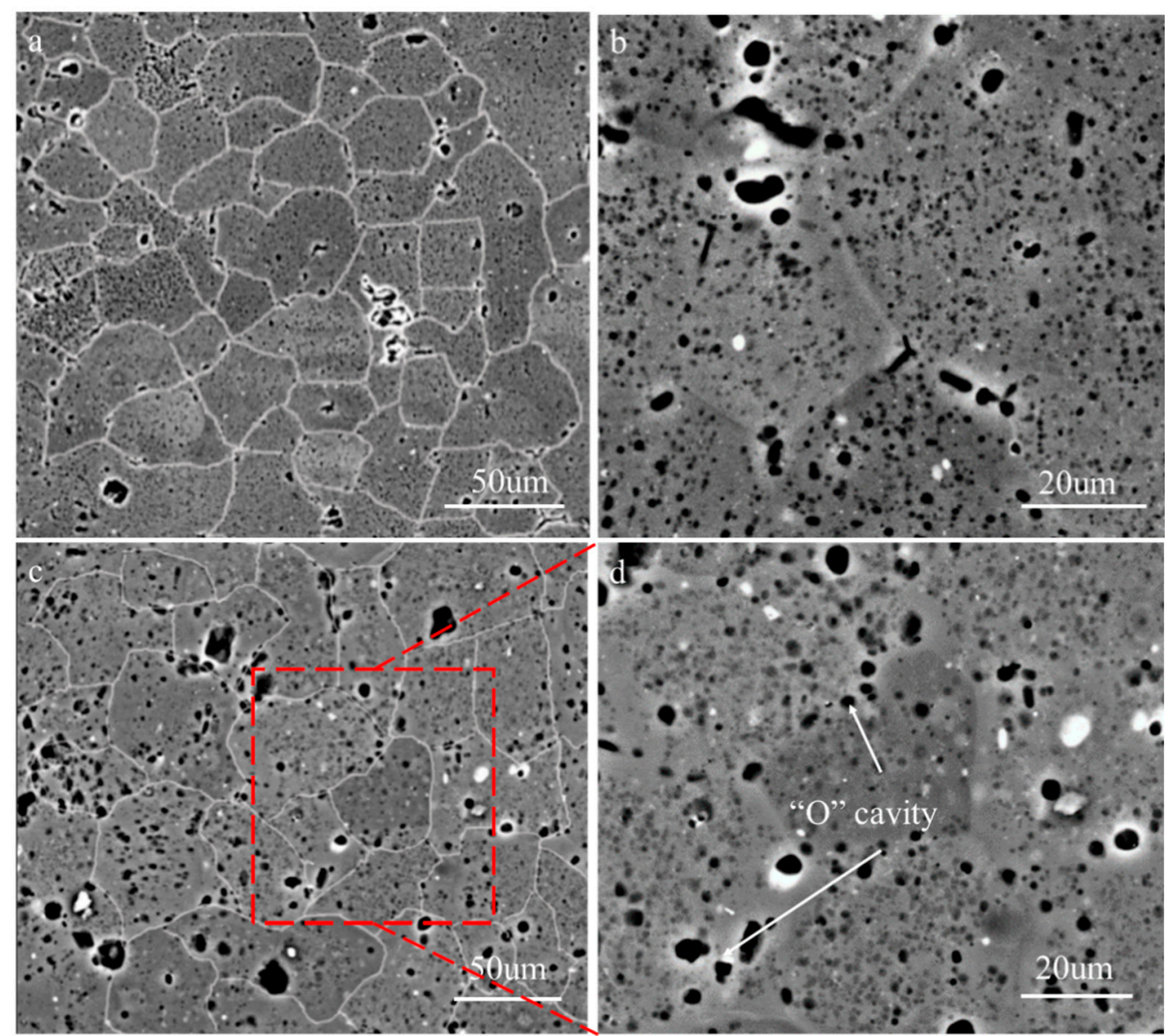

Figure 18. Microstructure of $(\mathbf{a}, \mathbf{b})$ the preforming structure; $(\mathbf{c}, \mathbf{d})$ final structure.

The cavity size grew with the increase of the deformation and holding time. It has been reported that most cavities nucleated at the interfaces between the particle and the matrix at both the grain boundary and the grain interior [34]. With the increase of deformation and insulation time, the size of the cavity increased gradually. As seen in Figure 18c,d, some cavities appeared at the grain boundary; however, these cavities were not interconnected. Therefore, the mechanical properties of the post-material decreased slightly. 


\section{Conclusions}

The mechanical properties of AA5083 were investigated at elevated temperatures, and the FEM established the structural design of the dies. Furthermore, the front fender was trial produced by a rapid SPF process. The following conclusions are drawn:

(1) Industrial AA5083 with the grain size of $20 \mu \mathrm{m}$ exhibited superplasticity at $480{ }^{\circ} \mathrm{C} / 0.001 \mathrm{~s}^{-1}$, and the maximum elongation was about $242 \%$ with the strain rate sensitivity value of 0.35 .

(2) The optimized design of the forming dies and the forming process could fabricate the fender with a complex shape.

(3) The front fender was successfully trial produced by the rapid SPF process, and the minimum thickness was $2.49 \mathrm{~mm}$ at the edge of the lamp orifice.

(4) The grain size increased by $15 \mu \mathrm{m}$ after the forming process. The tensile strength reduced by $5.78 \%$, and the elongation reduced by $18.5 \%$. The inharmonious grain boundaries sliding resulted in the appearance of cavities at the grain boundaries.

Author Contributions: Z.D., data collection, writing; G.W., study desigh; H.W., data analysis, figures. All authors have read and agreed to the published version of the manuscript.

Funding: This reseach was funded by the Henan Provincial Department of Science and Technology Research Project (Grant No. 182102210468), and National Natural Science Foundation of China (Grant No. 51875122). And the APC was funded by the Henan Provincial Department of Science and Technology Research Project (Grant No. 182102210468).

Institutional Review Board Statement: Not applicable.

Informed Consent Statement: Not applicable.

Data Availability Statement: Data sharing not applicable.

Acknowledgments: This work was supported by the Henan Provincial Department of Science and Technology Research Project (Grant No. 182102210468), and National Natural Science Foundation of China (Grant No. 51875122).

Conflicts of Interest: The authors declare no conflict of interest.

\section{References}

1. Ma, M.Y.; Wang, B.; Liu, H.Q.; Yi, D.Q.; Shen, F.H.; Zhai, T.G. Investigation of fatigue crack propagation behavior of 5083 aluminum alloy under various stress ratios: Role of grain boundary and schmid factor. Mater. Sci. Eng. A 2020, $773,138871$. [CrossRef]

2. Holroyd, N.J.H.; Burnett, T.L.; Seifi, M.; Lewandowski, J.J. Improved understanding of environment-induced cracking (EIC) of sensitized 5XXX series aluminum alloys. Mater. Sci. Eng. A 2017, 682, 613-621. [CrossRef]

3. Magee, A.C.; Ladani, L. Representation of a microstructure with bimodal grain size distribution through crystal plasticity and cohesive interface modeling. Mech. Mater. 2015, 82, 1-12. [CrossRef]

4. Magee, A.; Ladani, L.; Topping, T.D.; Lavernia, E.J. Effects of tensile test parameters on the mechanical properties of a bimodal Al-Mg alloy. Acta Mater. 2012, 60, 5838-5849. [CrossRef]

5. Jin, H. Optimization of aluminum alloy AA5083 for superplastic and quick plastic forming. Metall. Mater. Trans. A 2019, 50, 3868-3890. [CrossRef]

6. Giuliano, G.; Samani, F. Comparison between superplastic and non-superplastic grade AA 5083. J. Test. Eval. 2016, 44, 2114-2119. [CrossRef]

7. Krajewski, P.E.; Schroth, J.G. Overview of quick plastic forming technology. Mater. Sci. Forum 2007, 551, 3-12. [CrossRef]

8. Liu, J.; Tan, M.J.; Lim, C.V.S.; Chua, B.W. Process optimization and microstructural development during superplastic-like forming of AA5083. Int. J. Adv. Manuf. Technol. 2013, 69, 2415-2422. [CrossRef]

9. Liu, J.; Tan, M.J.; Aue-u-lan, Y.; Jarfors, A.E.W.; Fong, K.S.; Castagne, S. Superplastic-like forming of non-superplastic AA5083 combined with mechanical pre-forming. Int. J. Adv. Manuf. Technol. 2011, 52, 123-129. [CrossRef]

10. Barnes, A.J.; Raman, H.; Lowerson, A.; Edwards, D. Recent application of superformed 5083 aluminum alloy in the aerospace industry. Mater. Sci. Forum 2012, 735, 361-371. [CrossRef]

11. Hefti, L.D. Co mmercial airplane applications of superplastically formed AA5083 aluminum sheet. J. Mater. Eng. Perform. 2007, 16, 136-141. [CrossRef]

12. Park, H.S.; Dang, X.P.; Roderburg, A.; Nau, B. Development of plastic front side panels for green cars. CIRP J. Manuf. Sci. Technol. 2013, 6, 44-52. [CrossRef] 
13. Tao, W.; Liu, Z.; Zhu, P.; Zhu, C.; Chen, W. Multi-scale design of three dimensional woven composite automobile fender using modified particle swarm optimization algorithm. Compos. Struct. 2017, 181, 73-83. [CrossRef]

14. Hu, W.; Yao, L.G.; Hua, Z.Z. Optimization of sheet metal forming processes by adaptive response surface based on intelligent sampling method. J. Mater. Process. Technol. 2008, 197, 77-88. [CrossRef]

15. Fan, Z.J.; Gui, L.J.; Su, R.Y. Research and development of automotive lightweight technology. J. Automo. Saf. Energy 2014, 5, 1-16.

16. Park, H.S.; Nguyen, T.T. Optimization of injection molding process for car fender in consideration of energy efficiency and product quality. J. Comput. Des. Eng. 2014, 1, 256-265. [CrossRef]

17. Roth, R.; Clark, J.; Kelkar, A. Automobile bodies: Can aluminum be an economical alternative to steel? JOM 2001, 53, 28-32. [CrossRef]

18. Zhang, K.F.; Jiang, S.S. Superplastic forming. In Comprehensive Materials Processing, 1st ed.; Hashmi, S., Batalha, G.F., van Tyne, C.J., Yilbas, B., McGeough, J., Eds.; Elsevier: Amsterdam, The Netherlands, 2014; Volume 5, pp. 371-392.

19. Jafar, R.A.; Jarrar, F.S.; Al-Huniti, N.S. Two-stage approach for improving the thickness distribution in superplastic forming. J. Mater. Sci. Res. 2015, 4, 12-27. [CrossRef]

20. Jarrar, F.S.; Liewald, M.; Schmid, P.; Fortanier, A. Superplastic forming of triangular channels with sharp radii. J. Mater. Eng. Perform. 2014, 23, 1313-1320. [CrossRef]

21. Zhang, K.F.; Wang, G.F.; Wu, D.Z.; Wang, Z.R. Research on the controlling of the thickness distribution in superplastic forming. J. Mater. Process. Technol. 2004, 151, 54-57. [CrossRef]

22. Xing, H.L.; Zhang, K.F.; Wang, Z.R. A preform design method for sheet superplastic bulging with finite element modeling. J. Mater. Process. Technol. 2004, 151, 284-288. [CrossRef]

23. Jarrar, F.S.; Jr, L.G.H.; Khraisheh, M.K.; Bower, A.F. New approach to gas pressure profile prediction for high temperature AA5083 sheet forming. J. Mater. Process. Technol. 2010, 210, 825-834. [CrossRef]

24. Lan, H.C.; Fuh, Y.K.; Lee, S.; Chu, C.L.; Chang, T.C. Two-stage superplastic forming of a V-shaped aluminum sheet into a trough with deep and irregular contour. J. Mater. Eng. Perform. 2013, 22, 2241-2246. [CrossRef]

25. Xu, C.; Langdon, T.G.; Horita, Z.; Furukawa, M. Using equal-channel angular pressing for the production of superplastic aluminum and magnesium alloys. J. Mater. Eng. Perform. 2004, 13, 683-690. [CrossRef]

26. Hojjati, M.H.; Zoorabadi, M.; Hosseinipour, S.J. Optimization of superplastic hydroforming process of Aluminium alloy 5083. J. Mater. Process. Technol. 2008, 205, 482-488. [CrossRef]

27. Ko, Y.G.; Shin, D.H.; Park, K.T.; Lee, C.S. Superplastic deformation behavior of ultra-fine-grained $5083 \mathrm{Al}$ alloy using loadrelaxation tests. Mater. Sci. Eng. A 2007, 449, 756-760. [CrossRef]

28. Balasubramanian, M.; Stalin, B.; Ramanathan, K.; Ravichandran, M. Hot tensile test for determining the material constant on superplastic 5083Al alloy sheet. Mater. Today Proc. 2020, 21, 324-328. [CrossRef]

29. Taleff, E.M.; Wadsworth, L.J. Enhanced ductility in coarse-grained Al-Mg alloys. Metall. Mater. Trans. A 1996, $27,343-352$. [CrossRef]

30. Chezan, A.R.; de Hosson, J.T.M. Superplastic behavior of coarse-grained aluminum alloys. Mater. Sci. Eng. A 2005, 410, 120-123. [CrossRef]

31. Qiao, J.; Taleff, E.M. Superplasticity-like creep behavior of coarse grained ternary Al alloys. Trans. Nonferrous Met. Soc. China 2010, 20, 564-571. [CrossRef]

32. Sherby, O.D.; Taleff, E.M. Influence of grain size, solute atoms and second-phase particles on creep behavior of polycrystalline solids. Mater. Sci. Eng. A 2002, 322, 89-99. [CrossRef]

33. Bae, D.H.; Ghosh, A.K. Grain size and temperature dependence of superplastic deformation in an Al-Mg alloy under isostructural condition. Acta. Mater. 2000, 48, 1207-1224. [CrossRef]

34. Iwasaki, H.; Mori, T.; Hosokawa, H.; Tagata, T.; Mabuchi, M.; Higashi, K. Cavitation behavior of coarse-grained Al-4.5Mg alloy exhibiting superplastic-like elongation. Mrs Proc. 1999, 601, 67-72. [CrossRef] 